\title{
Adolescent health screening practices by physicians in Jamaica
}

\author{
Abigail Harrison, ${ }^{1}$ Russell Pierre, ${ }^{1}$ Georgiana Gordon-Strachan, ${ }^{2}$ \\ Sheila Campbell-Forrester, ${ }^{3}$ and Karen Leslie 4
}

Suggested citation Harrison A, Pierre R, Gordon-Strachan G, Campbell-Forrester S, Leslie K. Adolescent health screening practices by physicians in Jamaica. Rev Panam Salud Publica. 2011;29(4):252-8.

ABSTRACT Objective. To review Jamaican physicians' adolescent health screening practices by determining their frequency in areas of biomedical, psychological, social, and educational health; the factors that influence these practices; and physicians' perceived level of self-efficacy and their awareness of screening tools and guidelines.

Methods. A questionnaire was mailed to general practitioners, family medicine specialists, and pediatricians in Jamaica. The primary outcome variable was the frequency of physician screening for a range of biomedical, psychosocial, and educational developmental issues in the majority $(\geq 50 \%)$ of adolescent patients. Bivariate analyses were performed to determine differences between professional groups.

Results. The response rate was 32.3\% ( $\mathrm{n}=213$ ), with 209 responders being suitable for further analysis. The sample comprised $48.8 \%$ general practitioners, $33.0 \%$ family medicine specialists, and 18.2\% pediatricians. Physicians more often screened for biomedical risks than for psychosocial risks, with very low frequencies of screening for psychosocial issues such as mood, suicidal ideation, sexual orientation, and safety concerns. Physicians reported high levels of confidence in discussing most psychosocial issues with adolescent patients. Time limitation and an insufficient knowledge base were the main factors identified as influencing screening practices.

Conclusions. The data suggest unsatisfactory frequency of adolescent health screening by Jamaican physicians, in particular for psychosocial factors. The primary factors identified by physicians as influencing their screening practices have potential for improvement through continued medical education.

Key words Adolescent health; physician's practice patterns; Jamaica.

Adolescence is a complex and dynamic developmental period between ages 10 and 19 years (1) involving simultaneous yet asynchronous physical, sexual, cognitive, and socioemotional development.

1 Department of Child Health, University of the West Indies, Mona, Jamaica. Send correspondence to: Abigail Harrison, abby@cwjamaica.com

2 Faculty of Medical Sciences, University of the West Indies, Mona, Jamaica.

3 Ministry of Health, Kingston, Jamaica.

4 Department of Paediatrics, Division of Adolescent Medicine, University of Toronto, Toronto, Ontario, Canada.
Many potentially harmful lifestyle habits and behaviors are initiated during adolescence, indicating this period as an ideal time for primary prevention $(2,3)$. Adolescent morbidity and mortality are primarily due to preventable causes including substance use, unintentional injuries, unprotected sex and the associated risks of teen pregnancies, and sexually transmitted infections including HIV (4). Health professionals can play a significant role in reducing risk-related behaviors and promoting the healthy growth, development, and behavior of adolescent patients (2, 5-9).

Many health organizations have established clinical care guidelines for preventive adolescent health care (10-12), recommending periodic screening for behaviors that may affect adolescents' health and further assessment for those adolescents identified as at risk.

Physicians have been proposed as the gateway providers for adolescents, facilitating their access to other resources when appropriate (13). However, physi- 
cians in clinical service face many competing demands - such as time limitation during acute care visits, patient preferences, limited resources, and administrative factors-that may act as barriers to the provision of preventive health services $(14,15)$. Improved understanding of physicians' needs, their knowledge of available resources, and the environment in which they practice can therefore inform the development of policies that regulate health care services for adolescents. Additionally, there are factors inherent to physicians that may influence their adherence to screening recommendations, including low self-efficacy and outcome expectancy, a lack of familiarity with preventive health guidelines, and limited motivation to change due to comfort with present practices (16).

In Jamaica, adolescents aged 10 to 19 years compose $19.5 \%$ of the total population (17). Their health care issues represent a significant financial strain on the health care system, in particular the morbidity and mortality of intentional and unintentional injuries. There is no national policy in Jamaica stipulating regular health maintenance visits during adolescence and there are no formalized clinical guidelines for adolescent primary health care. An adolescent-focused group in Jamaica, Youth.now, developed the Jamaican Guidelines for Adolescent Reproductive Health Service Delivery (18) based on the Guidelines for Adolescent Preventive Services (GAPS) model (10) of the American Medical Association; however, this document is limited to sexual and reproductive issues in adolescents.

Although much data have been published on adolescent health screening and related physician practices in developed countries in North America, Europe, and Oceania (19-23), there is a paucity of data available on physicians' screening practices in Jamaica and the English-speaking Caribbean.

This study aimed to review the adolescent health screening practices of Jamaican physicians by determining the frequency of screening for biomedical, psychological, social, and educational health; the factors that influence screening practices; and physicians' level of self-efficacy in screening and awareness of available screening tools and guidelines. This process will provide data on perceived and unperceived needs in this area, which are particularly important for a resource-limited country so as to guide targeted changes in policies and procedures, optimizing outcome and minimizing unnecessary expenditure.

\section{MATERIALS AND METHODS}

\section{Participants}

A list of physicians practicing in Jamaica was obtained from the Medical Council of Jamaica and relevant professional associations (916 physicians). The list was stratified according to physicians involved in adolescent primary care [general practitioners (GPs), family medicine specialists (FMSs), and pediatricians] and excluded those not currently practicing in Jamaica, with a resultant sample of 643 eligible physicians.

\section{Data collection}

A 30-item questionnaire was developed, guided by a previously administered survey instrument used for a similar purpose in the United States of America (24). Modifications were implemented to increase the ease of administration and the likelihood of physicians completing the questionnaire by making the instrument more user-friendly for this study population. The questionnaire inquired about physicians' screening for risk and resiliency factors through verbal communication with adolescents during clinical encounters.

The following areas were included in the questionnaire:

- Demographic characteristics of physicians (gender, year of graduation from medical school, postgraduate training),

- Characteristics of the patient population seen (age and gender of patients, number of patients seen weekly),

- Physician confidentiality policies and practices,

- Biomedical screening (immunization status, blood pressure measurement, height, and weight),

- Psychosocial screening (family and peer relationships, sex and sexuality, mood disorders, substance use, school performance, and history of physical and sexual abuse),

- Education and counseling of patients and their parents, and

- Factors affecting physicians' screening practices (knowledge, confidence level, time restraints).
The questionnaire was piloted on 12 physicians representative of the study participants. They reported on ease in completing the questionnaire and suggested that the time for completing it be quoted as 20 minutes. No changes in content of the questionnaire were suggested or made.

Data were collated between October 2008 and April 2009. The questionnaire was mailed to 643 physicians in months 1 and 2 with a cover letter explaining the purpose of the study as well as a prestamped return envelope for completed questionnaires. A second mailing was done 4 to 8 weeks later in months 4 and 5 with a follow-up telephone call 6 weeks thereafter, in months 6 and 7 , to thank participants and encourage those who had not returned their questionnaire to do so $(25,26)$. Questionnaires were coded to allow for anonymity of respondents.

\section{Outcome variables}

The primary outcome variable was the frequency of physician screening for a range of biomedical, psychological, social, and educational developmental issues in the majority ( $\geq 50 \%$ ) of adolescent patients.

\section{Data analysis}

Statistical analysis was conducted within three subgroups of physiciansGPs, FMSs, and pediatricians-based on the differences in adolescent primary care training they would have received. FMSs and GPs see a similar profile of patients in similar clinical settings in Jamaica; however, as part of their postgraduate education FMSs would have received more training in adolescent health care. Similarly, pediatricians would also have received postgraduate training.

Bivariate analyses were performed with the Statistical Package for Social Sciences (27) to determine differences between physician groups. Chi-square tests were used to test for statistical significance among categorical variables. Fisher's exact test was used where crosstabulation cell numbers were less than 5 .

Ethical approval was obtained for this study from the University Hospital of the West Indies, University of the West Indies, Faculty of Medical Sciences Ethics Committee (Mona, Jamaica), Min- 
istry of Health's Ethics Board (Jamaica), and Hospital for Sick Children Research Ethics Board (Toronto, Canada).

\section{RESULTS}

Initially, 643 physicians were contacted by mail, with 45 physicians later excluded due to an incorrect mailing address, being out of the country, or not currently providing care to adolescents. For the remaining sample $(n=598)$ the response rate was $35.6 \%$ (213). No significant gender difference was noted (male $44.9 \%$, female $55.1 \%$ ). GPs represented $48.8 \%$ (102), the largest share of the study population.

Most physicians surveyed reported seeing the majority of their adolescents in private practice $(74.6 \%)$, with similar representation of male and female patients and most visits being for acute care $(64.6 \%)$. Less than half $(48.6 \%)$ of all physicians surveyed recommend annual health care visits for adolescents, and although the vast majority of physicians $(91.4 \%)$ reported providing confidential care to adolescent patients, less than $80 \%$ discussed their confidentiality policies with patients $(78.4 \%)$ and their parents (79.3\%) (Table 1).

\section{Biomedical and physical risk screening}

Most physicians assessed weight (71.0\%) and height (52.9\%) in the majority of patients, with pediatricians being significantly more likely to do so than GPs and FMSs $(P<0.005)$. Less than onequarter of physicians calculated the body mass index for most patients. The majority of physicians (74.5\%) assessed adolescents' blood pressure. As many as $81.8 \%$ of physicians asked girls about their menstrual history. Significantly more pediatricians reviewed immunization status $(P<0.001)$ and assessed sexual maturity staging $(P<0.001)$ in adolescent patients compared with other physicians. Less than $25 \%$ of physicians inquired about dieting for weight loss in most adolescents, and $61.2 \%$ of physicians asked about a family history of chronic illness.

\section{Psychosocial risk screening}

Most physicians $(60.8 \%)$ asked whether adolescents were sexually active; however, only $10.5 \%$ of physicians inquired whether adolescents' friends were engaging in sexual activity.

Less than $50 \%$ of physicians screened for substance use in the majority of adolescents (alcohol 33.0\%, cigarettes 37.3\%, illicit drugs $34.4 \%$ ) and less than onequarter of physicians reviewed substance use by adolescents' friends and family members. Almost $20 \%$ of physicians reported assessing adolescents' mood and $5.7 \%$ asked about suicidal ideation. Significantly more FMSs than GPs and pediatricians inquired about a family history of mental health issues $(P<0.05)$. Few physicians screened adolescents for safety concerns, including home safety $(9.2 \%)$, school safety $(9.6 \%)$, seatbelt use $(6.8 \%)$, and access to handguns $(2.4 \%)$. Pediatricians inquired more frequently about school performance $(89.5 \%)$ than GPs and FMSs $(P<0.0001)$ and FMSs $(47.8 \%)$ and pediatricians $(36.8 \%)$ inquired about adolescents' rela-

TABLE 1. Characteristics of physicians and their clinical practices, Jamaica, 2008-2009

\begin{tabular}{|c|c|c|c|c|}
\hline Characteristic & All physicians & GPs & FMSs & Pediatricians \\
\hline \multicolumn{5}{|l|}{ Median number of patients seen } \\
\hline per week (interquartile range) & $10(14)$ & $14(10)$ & $10(12)$ & $8(6)$ \\
\hline \multicolumn{5}{|l|}{ Patient gender, \% } \\
\hline Male & 45 & 37.2 & 36.6 & 44.3 \\
\hline Female & 55 & 61.6 & 60.0 & 55.4 \\
\hline \multicolumn{5}{|l|}{ Visit type, \% } \\
\hline$>50 \%$ routine & 33.3 & 31.7 & 29.0 & 44.7 \\
\hline$>50 \%$ sick & 64.6 & 69.5 & 66.7 & 50.0 \\
\hline \multicolumn{5}{|l|}{ Recommend annual health } \\
\hline visit, \% (No.) & 48.6 & $43.8(35)$ & $52.9(36)$ & $51.4(19)$ \\
\hline \multicolumn{5}{|l|}{ Provide confidential care to } \\
\hline adolescents, \% (No.) & 91.4 & \multicolumn{2}{|c|}{ Discuss confidentiality with } & $86.5(32)$ \\
\hline patients most of the time, \% (No.) & 78.4 & $76.9(63)$ & $79.7(55)$ & $78.9(30)$ \\
\hline \multicolumn{5}{|l|}{ Discuss confidentiality with } \\
\hline parents most of the time, \% (No.) & 79.3 & $78.0(64)$ & $81.1(56)$ & $79.0(30)$ \\
\hline
\end{tabular}

Note: GP: general practitioner, FMS: family medicine specialist. tionship with family members at home more frequently than GPs $(19.6 \%)(P<$ 0.001) (Table 2).

\section{Screening practices with at-risk adolescents}

Among adolescents identified as sexually active, most physicians inquired about contraception use $(71.8 \%)$ and the number of sexual partners the adolescent has had $(56.9 \%)$. Less than $10 \%$ of physicians provided condoms to adolescents regardless of the patient's gender (females $4.8 \%$, males $7.2 \%$ ) and $23.9 \%$ provided other birth control methods (including oral contraceptive pills). Just over one-half of physicians assessed the quantity and frequency of alcohol use in those adolescents identified as using alcohol, with $25.4 \%$ asking about driving under the influence of alcohol and $7.7 \%$ asking about ever having ridden in a car with the driver under the influence. Most physicians assessed the quantity of tobacco and illicit drugs used, but a minority asked about substance use by friends of the adolescent.

\section{Education and counseling practices}

Most physicians spoke with the parents of adolescent patients aged 16 years or less, with a minority speaking to parents of adolescents aged 17 to 19 years. Pediatricians were significantly more likely to speak with parents of older adolescents $(P<0.05)$. A minority of physicians reported discussing normal adolescent development and monitoring of adolescents' behavior with parents. Among at-risk adolescents, most physicians reported educating sexually active adolescents about the risks of sexually transmitted infections including HIV and substance users about the risks of alcohol, tobacco, and illicit drug use.

\section{Factors influencing physicians' screening practices}

Physicians reported confidence in discussing many psychosocial issues with adolescent patients; however, pediatricians were significantly less confident in discussing sexual activity, contraception, mood, and dieting for weight loss $(P<0.001)$ as well as body image, sexual abuse, and substance use $(P<0.05)$ (Table 3). 
TABLE 2. Physicians' adolescent health screening practices, Jamaica, 2008-2009

\begin{tabular}{|c|c|c|c|c|}
\hline \multirow[b]{2}{*}{ Area of screening } & \multicolumn{4}{|c|}{$\%$ who screen $\geq 50 \%$ of adolescent patients } \\
\hline & All physicians & GPs & FMSs & Pediatricians \\
\hline \multicolumn{5}{|l|}{ Biomedical factors } \\
\hline Immunizations & 42.0 & 30.3 & 37.7 & $81.6^{\mathrm{a}}$ \\
\hline Assess blood pressure & 74.5 & 70.3 & 83.6 & 70.3 \\
\hline Measure weight & 71.0 & 64.0 & 69.6 & $92.1^{\mathrm{b}}$ \\
\hline Measure height & 52.9 & 42.4 & 55.1 & $76.3^{b}$ \\
\hline Calculate body mass index & 17.2 & 12.1 & 25.8 & 15.8 \\
\hline Sexual maturity staging & 23.9 & 11.8 & 24.6 & $55.3^{a}$ \\
\hline Menstrual history & 81.8 & 77.5 & 87.0 & 84.2 \\
\hline Family history of chronic illness & 61.2 & 59.8 & 68.1 & 52.6 \\
\hline \multicolumn{5}{|l|}{ Physical factors } \\
\hline Sexual activity & 60.8 & 67.6 & 59.4 & $44.7^{\mathrm{b}}$ \\
\hline Friends' sexual activity & 10.5 & 9.8 & 13.0 & 7.9 \\
\hline Physical exercise & 46.4 & 40.2 & 47.8 & 60.5 \\
\hline Dieting for weight loss & 23.4 & 17.6 & 29.0 & 28.9 \\
\hline \multicolumn{5}{|l|}{ Psychosocial factors } \\
\hline School performance & 58.4 & 53.9 & 47.8 & 89.5 \\
\hline Relationship with family members & 32.1 & $19.6^{a}$ & 47.8 & 36.8 \\
\hline Mood & 19.6 & 13.7 & $29.0^{b}$ & 18.4 \\
\hline Suicidal ideation & 5.7 & 3.9 & 8.7 & 5.3 \\
\hline Family history of mental health issues & 32.5 & 29.4 & $47.8^{b}$ & 36.8 \\
\hline Sexual orientation & 9.6 & 6.9 & 14.5 & 7.9 \\
\hline \multicolumn{5}{|l|}{ Substance use } \\
\hline Alcohol & 33.0 & 34.3 & 36.2 & 23.7 \\
\hline Cigarettes & 37.3 & 40.2 & 40.6 & 23.7 \\
\hline Illicit drugs (marijuana, cocaine) & 34.4 & 36.3 & 37.7 & 23.7 \\
\hline Friends' substance use & 11.0 & 9.8 & 14.5 & 7.9 \\
\hline \multicolumn{5}{|l|}{ Safety issues } \\
\hline History of sexual abuse & 12.0 & 8.8 & 17.4 & 10.5 \\
\hline History of physical abuse & 8.1 & 15.9 & 11.6 & 7.9 \\
\hline Home safety & 9.2 & 3.9 & 10.1 & 5.3 \\
\hline School safety & 9.6 & 6.9 & 11.6 & 13.2 \\
\hline Seatbelt use & 6.8 & 4.9 & 7.2 & 2.6 \\
\hline Access to handguns & 2.4 & 1.0 & 5.8 & 0 \\
\hline
\end{tabular}

Note: GP: general practitioner, FMS: family medicine specialist.

a $P \leq 0.001$ (Pearson's chi-square test or Fisher's exact test).

b $P<0.05$ (Pearson's chi-square test or Fisher's exact test).

TABLE 3. Physicians' confidence level in discussing health-related issues with adolescent patients (28), Jamaica, 2008-2009

\begin{tabular}{lcccc}
\hline \multirow{2}{*}{ Issue } & \multicolumn{4}{c}{ \% somewhat or very confident } \\
\cline { 2 - 5 } & All physicians & GPs & FMSs & Pediatricians \\
\hline Sexual activity & 94.7 & 100 & 98.6 & $76.3^{\mathrm{a}}$ \\
Contraception & 95.7 & 100 & 98.5 & $81.1^{\mathrm{a}}$ \\
Sexual orientation & 63.9 & 66.7 & 79.1 & $63.9^{\mathrm{b}}$ \\
Sexual abuse & 83.3 & 85.0 & 88.0 & $71.1^{\mathrm{b}}$ \\
Physical abuse & 84.9 & 82.9 & 88.2 & $83.4^{\mathrm{b}}$ \\
Body image & 88.7 & 86.5 & 78.8 & $76.3^{\mathrm{b}}$ \\
Dieting for weight loss & 93.0 & 98.8 & 94.1 & $78.9^{\mathrm{a}}$ \\
Substance use & 89.8 & 91.3 & 93.1 & $78.9^{\mathrm{b}}$ \\
Mood disorder & 84.5 & 91.4 & 91.2 & $57.9^{\mathrm{a}}$ \\
\hline
\end{tabular}

Note: GP: general practitioner, FMS: family medicine specialist.

a $P<0.001$ (Fisher's exact test).

b $P<0.05$ (Fisher's exact test).

Physicians identified time limitation (40.2\%), insufficient knowledge base $(40.2 \%)$, and parents limiting access to confidential discussions with adolescent patients $(31.2 \%)$ as the primary factors that influenced their screening practices (Table 4). FMSs were more likely to report having received training in adoles- cent primary health care than GPs or pediatricians $(P<0.001)$, and nearly half of all physicians reported their knowledge base as insufficient to allow for appropriate screening of adolescent patients. Less than $2 \%$ of physicians reported low outcome expectancy and a minority of physicians was aware of screening tools used internationally $(10,28)$ including the HEADSS (29) psychosocial review. Most physicians (91.0\%) indicated an interest in participating in continued education in adolescent primary health care.

The results demonstrate that, of physicians surveyed, most see adolescents during acute care visits and do not recommend scheduled anticipatory care visits. Biomedical screening is performed significantly more frequently than screening for psychosocial concerns, with pediatricians reporting less confidence in discussing many psychosocial issues with adolescents as compared to GPs and FMSs. Physicians identified limited time and insufficient knowledge as the primary factors influencing their adolescent screening practices and reported limited training opportunities in adolescent primary care medicine.

\section{DISCUSSION}

Screening adolescents for risk and resiliency factors is an underpinning of preventive health care services, facilitating health promotion and disease prevention with appropriate and timely referrals in adolescents identified as being at risk. Many previously undetected health concerns-in particular psychosocial, emotional, and behavioral issuesmay be disclosed during screening at health visits (23) and allow for further management when required. In a resource-limited setting such as Jamaica, preventive care with appropriate anticipatory guidance must be seriously considered in an effort to minimize the need for secondary and tertiary care, which may be difficult to access.

Most Jamaican physicians surveyed did not recommend regular health maintenance visits, and although vaccination visits have been suggested as opportunities for adolescent screening in other countries $(30,31)$, Jamaica's national immunization schedule does not mandate any vaccines for adolescents, negating that prospect. Therefore, it would be prudent for Jamaican physicians to use all adolescent visits as opportunities for screening, including well and acute care visits $(6,32-34)$.

In Jamaica, the median age of sexual initiation is 13.0 years in males and 15.5 years in females; one-third of 10- to 15year-old adolescents drink alcohol and $10 \%$ smoke cigarettes, with even higher 
TABLE 4. Factors influencing physicians' screening practices with adolescents, Jamaica, 2008-2009

\begin{tabular}{|c|c|c|c|c|}
\hline \multirow[b]{2}{*}{ Factor } & \multicolumn{4}{|c|}{$\%$ influenced } \\
\hline & All physicians & GPs & FMSs & Pediatricians \\
\hline \multicolumn{5}{|l|}{ Received training in adolescent } \\
\hline \multicolumn{5}{|l|}{ Aware of HEADSS (29) } \\
\hline screening too & 14.1 & 6.1 & 13.8 & $32.4^{a}$ \\
\hline \multicolumn{5}{|l|}{ Aware of CRAFFT (28) } \\
\hline screening tool & 5.5 & 4.9 & 9.2 & 0 \\
\hline \multicolumn{5}{|l|}{ Aware of GAPS (10) } \\
\hline screening guidelines & 11.5 & 12.3 & 10.8 & 10.8 \\
\hline Insufficient knowledge base & 40.2 & 42.7 & 34.8 & 44.9 \\
\hline Limited impact on outcome & 0.5 & 0 & 1.9 & 0 \\
\hline \multicolumn{5}{|l|}{ External resources } \\
\hline Limited time & 40.2 & 43.9 & 39.1 & 34.2 \\
\hline Lack of appropriate space & 11.6 & 13.4 & 8.7 & 13.2 \\
\hline \multicolumn{5}{|l|}{$\begin{array}{l}\text { Parents limiting access to } \\
\text { confidential discussion with }\end{array}$} \\
\hline
\end{tabular}

rates among 16- to 19-year-old adolescents; $13 \%$ of 10 - to 15 -year-olds report a history of physical abuse $(35,36)$. Despite these compelling statistics, the frequency of screening for many psychosocial risk factors by Jamaican physicians in this study was low. Risky behaviors in adolescents tend to co-occur and increase with age (37-39), which suggests that regular adolescent health screening should start at an early stage.

Adolescents report valuing their physician's opinion on sensitive issues (40); although there may be initial hesitance, their receptivity to discussing sensitive topics increases if these topics are addressed by the physician on repeated occasions (33). They are also more likely to report that their health care provider understood their problems [odds ratio (OR) 3.62], eased their worries (OR 2.13), and allowed them to make decisions about (OR 2.71) and take some responsibility for (OR 2.00) their treatment when there had been discussion of at least one sensitive health topic (41). In addition, when adolescents understand and appreciate that their care is confidential they are more willing to seek health care, disclose information about behaviors associated with health risk, and return for follow-up, optimizing health providers' ability to offer appropriate care (42). Most physicians surveyed in this study reported offering confidential services; however, as many as $20 \%$ of them did not discuss their confidential policies with adolescents or parents to ensure the adolescent's understanding.
The findings in this study are not unlike those in developed countries (21, 24, $43,44)$, with significantly better frequencies of physicians' biomedical screening than psychosocial screening in adolescents. However, although difficult to directly compare studies given different methods and statistical analysis, the frequency of screening for psychosocial issues in this sample of Jamaican physicians appears to be significantly lower than that identified in North American studies $(21,24,43)$. This may be influenced by a lack of national guidelines recommending a standard of preventive health care for Jamaican adolescents.

In other studies, primary care physicians have reported feeling insufficiently trained in addressing many psychosocial concerns of youth, including substance use, unprotected heterosexual sex, samesex relationships, emotional difficulties, and abuse $(24,45)$. This may result in inadequate screening of patients at highest risk, who may benefit the most from early identification and intervention (15, 46). A minority of the Jamaican physicians surveyed reported training in adolescent primary care, with a lack of knowledge being reported as one of the primary factors influencing screening practices. Despite this fact, most physicians reported being confident in discussing psychosocial issues, except sexual orientation, which suggests that the low frequency of psychosocial screening may also be significantly affected by time limitation, another factor identified as a major barrier to screening in this study. Training physicians in the use of the HEADSS (29) tool as a means of engaging the adolescent, identifying risk and resiliency factors, and guiding the formulation of a management plan in a time-efficient manner would be ideal in a resource-limited setting, as the cost of printed or online access to screening questionnaires would be prohibitive.

An overwhelming majority of the physicians surveyed had an interest in continued education in adolescent primary health care. Training workshops aimed at increasing physicians' knowledge, attitudes, and skills to perform preventive screening with adolescents have been shown to be effective $(47,48)$ at increasing screening and counseling of adolescents. Screening and training in screening, however, is not the only answer, as it too has its challenges $(49,50)$. Further work needs to be done to determine what screening guidelines would be most beneficial (51) and cost-effective for Jamaican adolescents. Physicians also need further education on appropriate intervention and referrals where necessary in adolescents identified as at risk (52).

The perspectives of Jamaican adolescents would complement the findings of this study. Further research initiatives should include evaluating adolescents' perceptions of adolescent health care in Jamaica-what it is and what it should be to best meet their needs, thus providing the next generation of Jamaicans with the opportunity to help shape their own health outcomes.

The limitations of the study need to be considered. There was a relatively low response rate; however, this sample represented as much as one-third of all physicians providing primary care to adolescents in Jamaica. It is also possible that the physicians who responded may have a more keen interest in adolescent care than nonresponders, and so these frequencies may represent an overestimate of the national screening levels. There was no available relevant information on nonrespondents, precluding any comparison between the groups. Statistically, there was adequate representation for all physician subgroups to allow for satisfactory analysis. Physician responses were self-reported estimates and were not validated by chart review, which may result in some reporting bias, but chart reviews also have limitations (20). It is accepted that physicians may overestimate their responses in self- 
reported samples (53); however, we attempted to minimize this by ensuring anonymity of data collection.

Primary adolescent health care is performed by GPs, FMSs, and pediatricians in Jamaica. This study identified satisfactory biomedical screening and less than satisfactory levels of psychosocial screening in a large sample of Jamaican physicians. The main recommendations that arise from this work include increased ex- posure to and training in primary adolescent health care in the undergraduate medical curriculum and postgraduate pediatric and family medicine curricula. Targeted continued educational programs should also be made available for other registered physicians already involved in adolescent care. Educational efforts should emphasize as initial steps the importance of providing confidential services to adequately engage adolescents as well as satisfactory training in use of the inexpensive and user-friendly HEADSS (29) screening tool to identify protective and risk factors. The development of national guidelines for adolescent health care is also of paramount importance to increase physicians' awareness of ideal clinical practice parameters and to facilitate improved assessment, anticipatory guidance, and appropriate referrals for Jamaican adolescents.

\section{REFERENCES}

1. Society for Adolescent Medicine. Access to health care for adolescents and young adults. J Adolesc Health. 2004;35:342-4.

2. Breinbauer C, Maddaleno M. Youth: choices and change. Promoting healthy behaviours in adolescents. Washington, DC: PAHO; 2005. (Scientific and Technical Publication 594).

3. Young peoples' health-a challenge for society. Report of a WHO study group on young people and health for all by the year 2000 . Geneva: WHO; 1986. (Technical Report Series 731).

4. Ozer EM, Adams SH, Gardner LR, Mailloux DE, Wibbelsman CJ, Irwin CE, Jr. Provider self-efficacy and the screening of adolescents for risky health behaviors. J Adolesc Health. 2004;35(2):101-7.

5. Blum RW, Beuhring $T$, Wunderlich $M$, Resnick MD. Don't ask, they won't tell: the quality of adolescent health screening in five practice settings. Am J Public Health. 1996; 86(12):1767-72.

6. Suris JC, Nebot M, Parera N. Behaviour evaluation for risk-taking adolescents (BERTA): an easy to use and assess instrument to detect adolescent risky behaviours in a clinical setting. Eur J Pediatr. 2005;164(6):371-6.

7. Hedberg VA, Klein JD, Andresen E. Health counseling in adolescent preventive visits: effectiveness, current practices, and quality measurement. J Adolesc Health. 1998;23(6): 344-53.

8. Duncan PM, Garcia AC, Frankowski BL, Carey PA, Kallock EA, Dixon RD, et al. Inspiring healthy adolescent choices: a rationale for and guide to strength promotion in primary care. J Adolesc Health. 2007;41(6):525-35.

9. Park MJ, MacDonald TM, Ozer EM. Investing in clinical preventive health services for adolescents. San Francisco: University of California, Policy Information and Analysis Center for Middle Childhood and Adolescence and National Adolescent Health Information Center; 2001.

10. Elster AB, Kuznets NJ. AMA Guidelines for Adolescent Preventive Services (GAPS): recommendations and rationale. Baltimore, MD: Williams and Wilkins; 1994.

11. Elster AB. Comparison of recommendations for adolescent clinical preventive services developed by national organizations. Arch Pediatr Adolesc Med. 1998;152(2):193-8.
12. Green M, Palfrey JS. Bright futures: guidelines for health supervision of infants, children, and adolescents, 2nd ed. Arlington, VA: National Center for Education in Maternal and Child Health; 2002.

13. Stiffman AR, Pescosolido B, Cabassa LJ. Building a model to understand youth service access: the gateway provider model. Ment Health Serv Res. 2004;6(4):189-98.

14. Jaen CR, Stange KC, Nutting PA. Competing demands of primary care: a model for the delivery of clinical preventive services. J Fam Pract. 1994;38(2):166-71.

15. Van Hook S, Harris SK, Brooks T, Carey P, Kossack R, Kulig J, et al. The "Six T's": barriers to screening teens for substance abuse in primary care. J Adolesc Health. 2007;40(5): 456-61.

16. Cabana MD, Rand CS, Powe NR, Wu AW, Wilson MH, Abboud PA, et al. Why don't physicians follow clinical practice guidelines? A framework for improvement. JAMA. 1999;282(15):1458-65.

17. Statistical Institute of Jamaica. End of year population by age and sex 2009. Kingston, Jamaica: Statistical Institute of Jamaica; 2009. Available from: http://statinja.gov.jm. Accessed 6 February 2011.

18. Jamaica: Youth.now. Jamaican guidelines for adolescent reproductive health service delivery. Kingston, Jamaica: Ministry of Health; 2003.

19. Ercan O, Alikasifoglu M, Erginoz E, Janda J, Kabicek P, Rubino A, et al. Demography of adolescent health care delivery and training in Europe. Eur J Pediatr. 2009;168(4):417-26.

20. Yeo MS, Bond LM, Sawyer SM. Health risk screening in adolescents: room for improvement in a tertiary inpatient setting. Med J Aust. 2005;183(8):427-9.

21. Henry-Reid LM, O'Connor KG, Klein JD, Cooper E, Flynn P, Futterman DC. Current pediatrician practices in identifying high-risk behaviors of adolescents. Pediatrics. 2010; 125(4):e741-7.

22. Blum RW, Blum L, Phillips S, Smith P, Slap G. Adolescent health in Russia: a view from Moscow and St. Petersburg. J Adolesc Health. 1996;19(4):308-14.

23. Knishkowy B, Schein M, Kiderman A, Velber A, Edman R, Yaphe J. Preventive adolescent health care in family practice: a program summary. ScientificWorldJournal. 2006;6: 619-27.

24. Halpern-Felsher BL, Ozer EM, Millstein SG, Wibbelsman CJ, Fuster CD, Elster AB, et al. Preventive services in a health maintenance organization: how well do pediatricians screen and educate adolescent patients? Arch Pediatr Adolesc Med. 2000;154(2):173-9.

25. Dillman DA. Mail and Internet surveys. The tailored design method. Hoboken, NJ: John Wiley \& Sons, Inc.; 2000.

26. Asch DA, Jedrziewski MK, Christakis NA. Response rates to mail surveys published in medical journals. J Clin Epidemiol. 1997; 50(10):1129-36.

27. SPSS for Windows, Rel. 12.0. Chicago: SPSS, Inc.; 2006.

28. The CRAFFT screening tool. Boston, MA: Center for Adolescent Substance Abuse Research; 2009. Available from: http://www. ceasar-boston.org/CRAFFT/index.php. Accessed 6 February 2011.

29. Goldenring JM, Rosen DS. Getting into adolescent heads: an essential update. Contemp Pediatr. 2004;21:64.

30. Rupp R, Rosenthal SL, Middleman AB. Vaccination: an opportunity to enhance early adolescent preventative services. J Adolesc Health. 2006;39(4):461-4.

31. Broder KR, Cohn AC, Schwartz B, Klein JD, Fisher MM, Fishbein DB, et al. Adolescent immunizations and other clinical preventive services: a needle and a hook? Pediatrics. 2008;121(Suppl 1):S25-34.

32. Rand CM, Auinger P, Klein JD, Weitzman M. Preventive counseling at adolescent ambulatory visits. J Adolesc Health. 2005;37(2):87-93.

33. Steiner BD, Gest KL. Do adolescents want to hear preventive counseling messages in outpatient settings? J Fam Pract. 1996;43(4):375-81.

34. Hacker KA, Arsenault LN, Williams S, Digirolamo AM. Mental and behavioral health screening at preventive visits: opportunities for follow-up of patients who are nonadherent with the next preventive visit. J Pediatr. 2011; 158(4):666-71.

35. Fox K, Gordon-Strachan G. Jamaican youth risk and resiliency behaviour survey 2005 school-based survey on risk and resiliency behaviours of 10-15 year olds. 2007. Available from: http://www.cpc.unc.edu/measure/ publications. Accessed 6 February 2011. 
36. Wilks R, Younger N, McFarlane S, Van Den Broeck J. Jamaican youth risk and resiliency behaviour survey 2006: community-based survey on risk and resiliency behaviours of 15-19 year olds. 2007. Available from: http:// www.cpc.unc.edu/measure/publications/ tr-07-64. Accessed 6 February 2011.

37. Irwin $C E$, Jr., Igra $V$, Eyre $S$, Millstein S. Risktaking behavior in adolescents: the paradigm. Ann N Y Acad Sci. 1997;817:1-35.

38. Lindberg LD, Boggess S, Porter L, Williams S. Teen risk taking: a statistical portrait. Washington, DC: Department of Health and Human Services; 2000.

39. Brener ND, Collins JL. Co-occurrence of health-risk behaviors among adolescents in the United States. J Adolesc Health. 1998; 22(3):209-13.

40. Boekeloo BO, Schamus LA, Cheng TL, Simmens SJ. Young adolescents' comfort with discussion about sexual problems with their physician. Arch Pediatr Adolesc Med. 1996; 150(11):1146-52

41. Brown JD, Wissow LS. Discussion of sensitive health topics with youth during primary care visits: relationship to youth perceptions of care. J Adolesc Health. 2009;44(1): $48-54$.
42. Berlan ED, Bravender T. Confidentiality, consent, and caring for the adolescent patient. Curr Opin Pediatr. 2009;21(4):450-6.

43. Ellen JM, Franzgrote $M$, Irwin CE, Jr. Millstein SG. Primary care physicians' screening of adolescent patients: a survey of California physicians. J Adolesc Health. 1998;22(6): 433-8.

44. Ozer EM, Zahnd EG, Adams SH, Husting SR, Wibbelsman CJ, Norman KP, et al. Are adolescents being screened for emotional distress in primary care? J Adolesc Health. 2009; 44(6):520-7.

45. Blum R. Physicians' assessment of deficiencies and desire for training in adolescent care. J Med Educ. 1987;62(5):401-7.

46. Irwin CE, Jr., Adams SH, Park MJ, Newacheck PW. Preventive care for adolescents: few get visits and fewer get services. Pediatrics. 2009:123(4):e565-72.

47. Ozer EM, Adams SH, Lustig JL, Gee S, Garber AK, Gardner LR, et al. Increasing the screening and counseling of adolescents for risky health behaviors: a primary care intervention. Pediatrics. 2005;115(4):960-8.

48. Smith KD, Merchen E, Turner CD, Vaught C, Fritz T, Mold J. Improving the rate and quality of Medicaid well child care exams in pri- mary care practices. J Okla State Med Assoc. 2010;103(7):248-53.

49. Richmond TK, Freed GL, Clark SJ, Cabana MD, American Academy of Pediatrics, American Academy of Family Practice, et al. Guidelines for adolescent well care: is there consensus? Curr Opin Pediatr. 2006;18(4): 365-70.

50. Solberg LI, Nordin JD, Bryant TL, Kristensen AH, Maloney SK. Clinical preventive services for adolescents. Am J Prev Med. 2009;37(5): 445-54.

51. Maciosek MV, Coffield AB, Edwards NM Flottemesch TJ, Goodman MJ, Solberg LI. Priorities among effective clinical preventive services: results of a systematic review and analysis. Am J Prev Med. 2006;31(1):52-61.

52. Milne B, Towns S. Do paediatricians provide brief intervention for adolescents who smoke? J Paediatr Child Health. 2007;43(6): 464-8.

53. Lewis CE, Clancy C, Leake B, Schwartz JS. The counseling practices of internists. Ann Intern Med. 1991;114(1):54-8.

Manuscript received on 19 June 2010. Revised version accepted for publication on 8 February 2011.

RESUMEN Objetivo. Analizar las prácticas de examen sistemático de la salud de los adolescentes por parte de los médicos de Jamaica mediante la determinación de la frecuencia con la que llevan a cabo reconocimientos sistemáticos de salud en las áreas biomédica, psicológica, social y educativa; los factores que afectan dichas prácticas sistemáticas; el nivel de autoeficacia percibida por los médicos respecto a ellas y su conocimiento de los instrumentos y las recomendaciones con respecto a los exámenes sistemáticos.

Métodos. Se envió por correo un cuestionario a médicos generales, especialistas en medicina familiar y pediatras de Jamaica. La principal variable de evaluación fue la frecuencia con la que los médicos llevan a cabo exámenes sistemáticos sobre varios aspectos biomédicos, psicosociales y del desarrollo educativo en la mayoría ( $\geq 50 \%$ ) de los pacientes adolescentes. Se realizaron análisis bifactoriales a fin de establecer las diferencias entre los grupos de profesionales.

Resultados. La tasa de respuesta fue de 32,3\% ( $n=213)$ y se consideró que 209 participantes eran adecuados para el análisis posterior. En la muestra, 48,8\% eran médicos generales, $33,0 \%$ eran especialistas en medicina familiar y 18,2\% eran pediatras. Los médicos llevaban a cabo exámenes sistemáticos con más frecuencia para evaluar los riesgos biomédicos que los riesgos psicosociales, y los exámenes sobre aspectos psicosociales como el estado de ánimo, la presencia de ideas suicidas, la orientación sexual y temas relacionados con la seguridad se exploraron muy poco. Los médicos informaron altos niveles de confianza para tratar la mayoría de los temas psicosociales con los pacientes adolescentes. Los principales factores que afectaran las prácticas de examen sistemático fueron la falta de tiempo y la carencia de conocimientos suficientes.

Conclusiones. Los datos indican que la frecuencia con la que los médicos de Jamaica llevan a cabo prácticas de examen sistemático relacionadas con la salud de los adolescentes es insuficiente, en particular en lo que respecta a los factores psicosociales. Los principales factores que, según los médicos, afectan sus prácticas con respecto a este tema pueden mejorarse mediante programas de formación médica continua.

Palabras clave Salud del adolescente; pautas en la práctica de los médicos; Jamaica. 